\title{
INFORMES*
}

\section{El Instituto Andaluz de Patrimonio Histórico}

\section{INTRODUCCIÓN}

La Ley 5/2007, de 26 de junio (BOJA núm. 131, de 4 de julio) crea como entidad de derecho público el Instituto Andaluz de Patrimonio Histórico (IAPH). No se trata de una creación ex novo, pues el IAHP ya existía como servicio sin personalidad jurídica propia creado por el Decreto 107/1989, de 16 de mayo. Se viene a engrosar la nómina de entes públicos instrumentales que con diversa denominación, muchas veces sin más justificación que la inercia de una tradición, se integran en la estructura de la Administración de la Junta de Andalucía.

Antes de proceder, como en otros números de esta Sección, a exponer los rasgos de este nuevo ente público conviene detenerse, siquiera brevemente, en el contexto y pasar la vista por el abigarrado mundo que constituyen estas entidades en la Junta de Andalucía.

En estos años se han creado cuatro agencias de las que dos son organismos autónomos al amparo del art. 4.1 a. de la Ley General 5/1983, de 19 de julio, de Hacienda Pública de la Comunidad Autónoma de Andalucía (Agencia Andaluza del Agua, creada por Ley 3/2004, de 28 de diciembre, y Agencia Andaluza de Evaluación de la Calidad y Acreditación Universitaria, creada por Ley 15/2003, de 22 de diciembre) y dos son entidades de derecho público que por ley han de ajustar sus actividades al derecho privado, según el art. 6. 1. b de la misma Ley (Agencia Andaluza de Cooperación Internacional para el Desarrollo, Ley 2/2006, de 16 de mayo y Agencia Andaluza de la Energía, Ley 4/2003, de 23 de septiembre). Se han creado o, elevados al rango de entidad con personalidad jurídica tres institutos; de ellos dos son organismos autónomos (Instituto Andaluz de Prevención de Riesgos Laborales, Ley 10/2007, de 26 de diciembre y el Instituto Andaluz de Investigación y Formación Agraria, Pesquera, Alimentaria y de Producción Ecológica, Ley

\footnotetext{
${ }^{1}$ Esta Sección ha sido preparada bajo la dirección de José Ignacio Morillo-Velarde Pérez.
} 
1/2003, de 10 e abril) y el otro es entidad de derecho público de las referidas con anterioridad (Instituto Andaluz de Patrimonio Histórico, a que se refieren estas líneas). Los otros tres entes, con denominaciones heterogéneas y diversas entre si, tampoco tienen la misma naturaleza jurídica. Dos son entidades del art. 6. 1. b de la Ley 5/1983 (Empresa Pública Sanitaria del Bajo Guadalquivir, Ley 3/2006, de 19 de junio y Ente Público de Gestión de los Ferrocarriles Andaluces, Ley 2/2003, de12 de mayo) y el otro, organismo autónomo (Servicio Andaluz de Empleo, Ley 4/2002, de 16 de diciembre).

Incluso, este año hemos visto como se aprueba los estatutos de la de la Agencia de Innovación y Desarrollo de Andalucía, por Decreto 26/2007, de 6 de febrero. Esta Agencia empezó siendo el Instituto de Fomento de Andalucía, creado por Ley 3/1987, de 13 de abril al que cambió de nombre la Ley $3 / 2004$, de 28 de diciembre.

Llama la atención como las denominaciones agencia e instituto se aplican sin ningún tipo de criterio pues lo mismo aluden a un organismo autónomo que a a una entidad de derecho público sometida al derecho privado. En la serie que hemos observado no hay elementos suficientes para inducirlo ni siquiera desde el punto de vista estadístico. Acaso si la prolongáramos podríamos atisbar alguno, pero sería simplemente un dato estadístico que no es probable que arrojara más luz. Por otro lado, si contrastáramos la denominación agencia con la homologa estatal, tampoco obtendríamos pista alguna.

Tal vez la respuesta al problema nos la de Proyecto de Ley de Administración de la Junta de Andalucía, cuando se convierta en ley. Efectivamente y, sin entrar en el enjuiciamiento de ningún aspecto de su texto, por lo menos es de encomiar el propósito que persigue: La norma define, en aras de una adecuada racionalización del sector público, las distintas entidades vinculadas o dependientes de la Administración de la Junta de Andalucía. Ha de notarse, en este sentido, que la terminología empleada por la Ley es del todo novedosa, reservando la categoría de "agencias administrativas" para los organismos autónomos a los que se refería el artículo 4 de la Ley General de la Hacienda de la Comunidad Autónoma de Andalucía, y la de "agencias públicas empresariales" para las entidades de derecho público del artículo 6.1 b) de la citada Ley, y además se introduce una nueva categoría, denominada "agencia de régimen especial", con ciertas peculiaridades en su régimen de personal, presupuestario y de gestión de su actividad, atendiendo a la naturaleza de las funciones asignadas que implican ejercicio de autoridad. Pero este cambio terminológico no es un mero prurito formal, sino que refleja adecuadamente la naturaleza jurídica y el subsiguiente régimen que corresponden a las distintas personificaciones que nuestro Derecho conoce. En esta linea, la Ley realiza un considerable esfuerzo por definir y sujetar a cada una de estas 
entidades al ámbito de actuación material que le es propio en consonancia con las exigencias inherentes a su respectiva naturaleza jurídica (Exposición de motivos).

En el futuro todas estas entidades serán agencias diversificándose dentro de ellas las agencias administrativas, sucesoras de los organismos autónomos de las agencias públicas empresariales. Se supone que las administrativas también son públicas y que este calificativo a quien realmente define es a la empresa, pero es obvio que la expresión agencia empresarial pública no suena bien y, por otro lado, no se hace sino reeditar el mismo fenómeno de la LOFAGE (Ley 6/1997, de 14 de abril, de organización y funcionamiento de la Administración General del Estado) contraponiendo la entidad pública empresarial al organismo autónomo en el marco de los organismos públicos. Sin embargo nos tememos que la racionalización que con tanto acierto pretende la exposición de motivos de la futura norma andaluza no ha de llegar a su denominación, pues no parece preocupar en el texto proyectado el baile de denominaciones de entes instrumentales que estamos denunciando. Si en el proyecto el Instituto Andaluz de Administración Pública es una agencia administrativa y antes era un organismo autónomo todo hace pensar que el Instituto Andaluz de Patrimonio Histórico será una agencia pública empresarial. Seguramente las actuales agencias -que hemos visto unas serían administrativas y otras agencias públicas empresariales- serán los únicos entes obligados a cambiar de denominación, o incluso, quizá tampoco, puesto que tan escaso aprecio se hace de este aspecto. Es fácil convenir que no es una cuestión de la máxima importancia y que hay problemas más graves, mas cuando tanto se habla de transparencia, de racionalidad etc, acaso sería bueno que los interlocutores de estos entes pudieran tener una aproximación a los rasgos fundamentales de su régimen jurídico sin necesidad de acudir a la información del BOJA.

\section{FINES Y FUNCIONES DEL IAPH}

El Instituto Andaluz del Patrimonio Histórico se configura como un organismo cuyos fines son la intervención, investigación e innovación, documentación, comunicación y desarrollo del patrimonio cultural en el marco de los planes de investigación, desarrollo e innovación de la Junta de Andalucía

Para el cumplimiento de estos fines el IAPH realizará las funciones que le indica la ley, sin perjuicio de que puedan añadírsele otras por sus estatutos: 
a) El análisis, estudio, desarrollo y difusión de teorías, métodos y técnicas aplicadas a la tutela del patrimonio histórico y a su protección, conservación, gestión, investigación y difusión.

b) La realización de informes, diagnósticos, proyectos y actuaciones en materia de protección, intervención, documentación, investigación y comunicación de los bienes culturales.

c) El desarrollo de proyectos y actuaciones en materia de conservación y restauración del patrimonio histórico.

d) La realización de actuaciones en materia de investigación del patrimonio histórico en el ámbito de sus competencias.

e) La integración, coordinación y sistematización de la información y documentación en materia de patrimonio histórico, para contribuir al estudio y conocimiento de los bienes culturales de Andalucía.

f) El establecimiento de planes de formación de especialistas en los distintos campos del patrimonio histórico, promoviendo y organizando actividades formativas.

g) El fomento de la colaboración con instituciones privadas y organismos públicos en relación con las funciones del Instituto previstas en esta Ley y las que en su desarrollo se determinen en los estatutos, prestando especial atención a los convenios de colaboración con las Universidades públicas de Andalucía en materia de formación e investigación.

La lectura de este amplio elenco de funciones que, sin duda, será pormenorizado y desarrollado en los estatutos, evidencia cómo la fórmula jurídica de servicio sin personalidad, con que este órgano fue creado, ha quedado ampliamente superada y se impone la nueva estructura jurídica que se le atribuye por la ley en esta especie de refundación. Nos encontramos ante una manifestación más del intervencionismo administrativo que tiene que encargarse de unas funciones que lamentablemente no parecen interesar a la sociedad civil. Si es así bienvenido sea, de lo contrario, mejor sería reconsiderar hasta que punto el poder burocrático no hace sino ganar terreno a una sociedad abúlica y adormecida. En cualquier caso la propia existencia del organismo y el reforzamiento que supone su nueva regulación no es una buena noticia para Andalucía, pues por unas u otras razones evidencia una sociedad tutelada desde las instancias oficiales y burocráticas.

\section{RÉGIMEN JURÍDICO}

De la lectura de las funciones que hemos reseñado en el apartado anterior se desprende que el IAPH busca con su nueva regulación acceder al 
régimen jurídico privado, coherente con unas actividades propias del sector privado. Esto tenía grandes limitaciones en su estructura anterior de servicio sin personalidad. La realidad es que mediante esta ley lo que antes era Administración pasa a ser empresa -pública, ciertamente pero empresa-y, en consecuencia, reclama el acogimiento al régimen adecuado que es el derecho privado, sin perjuicio de posibles excepciones que se consignen en la presente ley (art. 4. 1). Es evidente que el régimen de contratación, que se remite a la Ley de Contratos de las Administraciones Públicas y demás normativa que sea de aplicación, el régimen económico y presupuestario, sometido a la Ley General de Hacienda Pública de la Comunidad Autónoma, el de su patrimonio, que se rige por la Ley de Patrimonio de la Comunidad Autónoma, son expresiones de derecho público, pero las relaciones con su personal se regulan por el derecho laboral y el resto de su actividad pasan a regularse por el derecho privado. Incluso se echa de menos en esta ley un precepto estableciendo las vías de recurso administrativo y contencioso-administrativo contra actos de los órganos de gobierno de la entidad cuando ejerzan potestades públicas. La conclusión que se obtiene de ello es que, dadas las actividades que se encomiendan al Instituto, éste no va a ejercer potestades públicas en ningún caso. Su transformación en empresa es, por tanto, total.

\section{ORGANIZACIÓN}

La organización del IAPH es la habitual en este tipo de organizaciones, tanto si son organismos autónomos como si se trata de organizaciones empresariales:

A) Presidente que, como también es frecuente tanto en los organismos autónomos como entidades empresariales, recae en el titular-persona titular, según la Ley- de la Consejería competente en materia de cultura, con las funciones de:

a) Ostentar la superior representación institucional del Instituto.

b) Velar por el cumplimiento de los acuerdos del Consejo Rector.

c) Cualesquiera otras que se le atribuyan por los estatutos del Instituto.

B) Consejo Rector el máximo órgano de gobierno y dirección y está integrado por la persona que presida el Instituto, quien ostentará al mismo tiempo la Presidencia del Consejo, por la persona a quien se atribuya la Dirección, así como por los miembros que se establezcan en los estatutos. Esta deslegalización tan completa de la composición del máximo órgano de direc- 
ción y gobierno es expresión del pleno carácter burocrático de la institución, sin perjuicio, como es natural de que seguramente se establecerá un composición que no podrá sino de calificarse de participativa teniendo en cuenta órganos parecidos y las pautas de lo políticamente correcto en nuestras Administraciones públicas. Sin embargo, las funciones de esta consejo a tenor de la propia ley, son de lo más incoloro e insípido -no se quiere decir intrascendente- en el contexto de la actividad del instituto. Así establece la ley Son funciones del Consejo Rector:

a) Velar por el cumplimiento del ordenamiento jurídico en todas las actuaciones del Instituto.

b) Aprobar los anteproyectos del programa de actuación, inversión y financiación y de los presupuestos de explotación debe elaborar según lo dispuesto en el artículo 57 de la Ley 5/1983, de 19 de junio, General de la Hacienda Pública de la Comunidad Autónoma.

c) Acordar la creación de comisiones especializadas o grupos de trabajo en el seno del Instituto, definir su composición, así como determinar sus funciones.

d) Cualesquiera otras que le corresponda en virtud de los estatutos del Instituto.

C) El Director que será nombrado por quien ostente la titularidad de la Consejería competente en materia de cultura y tendrá a su cargo la gestión ordinaria de las actividades de la entidad, en ejecución de los acuerdos y directrices del Consejo Rector, de conformidad con las competencias que le asignen los estatutos. 